\title{
Performances of a Research CFR Octane Rating Unit Engine and Dacia Single Cylinder SI Engine Ignited by a LASER System
}

\author{
Bogdan George Done ${ }^{1}$, Ion Copae ${ }^{1}$ \\ ${ }^{1}$ Department of Military Vehicles and Transportations, Faculty of Aircraft and Military Vehicles, \\ "Ferdinand I" Technical Military Academy of Bucharest.
}

\begin{abstract}
At this time, the severe legislation regarding the level limits of the waste and exhaust gases released by thermal engines and also the necessity of engines efficiency improvement boost the engine research domain to bring in front the use of new technologies that can be used to control the in-cylinder combustion process. Now, the new technologies is represented by LASER spark plug systems which can be successfully used at petrol engines. LASER spark plug technology can have many advantages for engine operation control, an ignition system that could provide improved combustion is the one using plasma generation and a Qswitched LASER that results in pulses with high MW power. The LASER spark plug device used in the current research was a LASER medium Nd:YAG/Cr4+:YAG ceramic structure made up of a 8.0-mm long, 1.0at.\% Nd:YAG ceramic, optically-bonded to a Cr4+:YAG c. It was developed and constructed similar to classical spark plug and could be assembled on a CFR Octane Rating Unit Engine as well as on a Dacia Single Cylinder SI Engine which led to several results among which: influences on in-cylinder pressure, combustion and pollutant emissions.
\end{abstract}

Keywords: LASER spark plug, combustion, pollutant emissions, new technologies, pressures.

\section{Introduction}

Internal combustion engines are extremely important in transportation and energy production therefore any improvement will lead to a substantial decrease in pollutants and consequently greenhouse gases. Ignition is a complex phenomenon which greatly impacts combustion [1], especially the initial stages which result in pollutant formation, flame propagation as well as quenching. The ignition source has undergone few changes over the past hundred years. The classical spark plug is made up of two electrodes having a space between them, where an electrical arc is produced due to high voltage discharge. For several years researchers have been intent on finding a LASER based ignition source [2], which can replace a classical spark plug with a pulse focused LASER beam and they also attempted to control ignition by a LASER source [3]. The development of flame kernel size simultaneous with NOx production are highly important [4] and in this situation a LASER

*Corresponding author: bogdan.done@yahoo.fr 
spark plug source can improve engine combustion compared to classical spark plugs. Laser spark plug systems are intended to protect resources and the decrease $\mathrm{CO} 2$ emissions thus limiting the greenhouse effect. It could be obtained through lower fuel consumption achieved by the spark ignition (SI) engine system, owing to high thermodynamic capacity resulting from direct injection. One of the main drawbacks is that with classical spark ignition the place of ignition cannot be specifically chosen. LASER induced ignition could eliminate some of these difficulties. Several other ignition systems apart from LASER spark plug are reviewed [4] such as microwave ignition and high frequency ignition.

\section{LASER Spark Plug}

LASER spark plug is the chemical-kinetic mechanism of starting combustion by the stimulus of a LASER source. Scientific literature generally classifies energetic interactions of a LASER with a gas into four schemes [5], characterised by the nanosecond domain of the LASER pulse and the duration of the entire combustion could be several hundreds of milliseconds. It takes only a few nanoseconds for the LASER energy to be deposited followed by shock wave generation. Combustion may take from $100 \mathrm{~ms}$ to several seconds according to the air-fuel dosage, initial pressure, pulse energy, plasma size, plasma and initial temperature in the combustion chamber.

The following main advantages of LASER spark plug are as follows [6, 7, 8, 9 10]:

- a choice of arbitrary positioning of the ignition plasma in the combustion cylinder

- absence of quenching effects by the spark plug electrodes

- ignition of leaner mixtures than with the spark plug $\Rightarrow>$ lower combustion temperatures $=>$ less NOx emissions no erosion effects as in the case of the spark plugs $=>$ lifetime of a LASER spark plug system expected to be significantly longer than that of a spark plug

- $\quad$ high load/ignition pressures possible $=>$ increase in efficiency

- $\quad$ precise ignition timing possible

- $\quad$ exact regulation of the ignition energy deposited in the ignition plasma

- easier possibility of multipoint ignition

- $\quad$ shorter ignition delay time and shorter combustion time

- fuel-lean ignition possible

The disadvantages of LASER spark plug are:

- $\quad$ high system costs

- concept proven, but no commercial system available yet.

\section{Experimental investigation}

Experimental investigations were carried out in a research laboratory of the Faculty of Mechanical Engineering and Mechatronics, Department of Thermotechnics, Engines, Thermal Equipments and Refrigeration Installations, University POLITEHNICA of Bucharest.

This section describes the experimental research which was developed on an experimental single cylinder SI engine, equipped with LASER spark plug. The Dacia Single Cylinder SI Engine figure 1, indicates a speed of $2800 \mathrm{rev} / \mathrm{min}$, a $90 \%$ load and the CFR Octane Rating Unit Engine figure 2, shows a speed of $900 \mathrm{rev} / \mathrm{min}$. Both experimental engines were single-cylinder and were mounted on test beds adequately instrumented. A photo of the LASER spark provided by INFLPR, Laboratory of Solid-State Quantum Electronics, Magurele, Romania is shown in figure 3, with the technical details for the LASER to be found in articles $[11,12,13]$. 


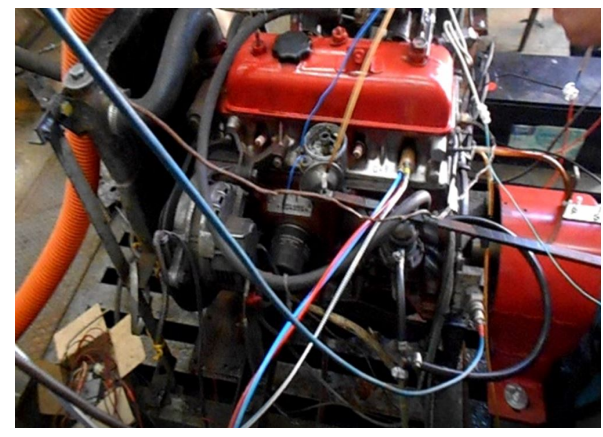

Fig. 1. Dacia Single Cylinder SI Engine equipped with LASER spark plug

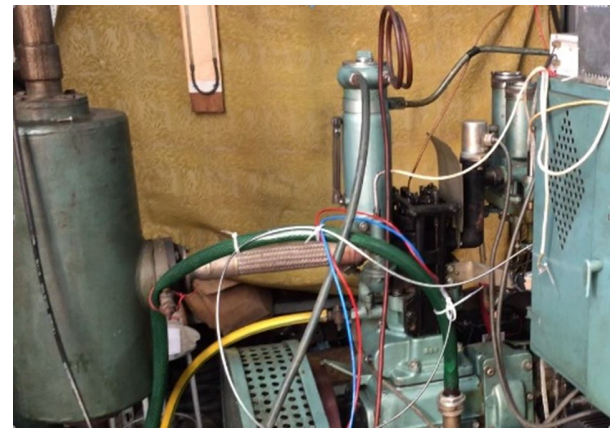

Fig. 2. CFR Octane Rating Unit Engine equipped with LASER spark plug

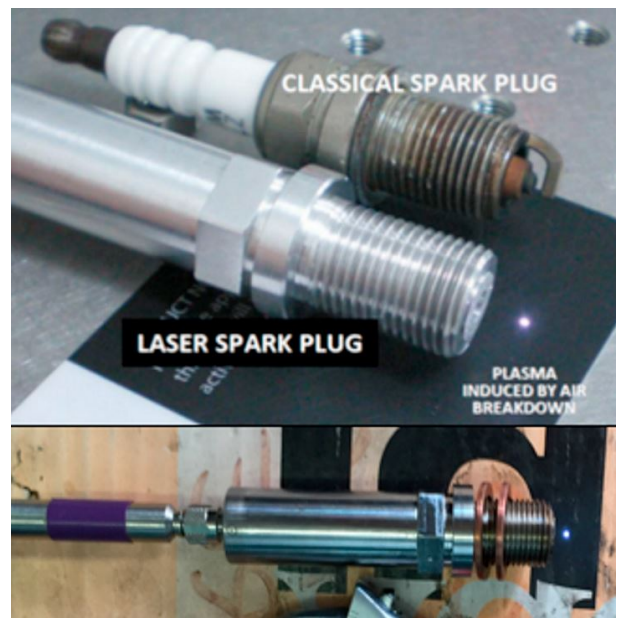

Fig. 3. A photo of a LASER spark plug is shown in comparison with a classical spark plug. The plasma induced in air by optical breakdown is visible.

(Courtesy of INFLPR, Laboratory of Solid-State Quantum Electronics, Magurele, Romania)

\section{Results and discussion}

Figure 4 shows the pressure curves indicated for the two types of spark plugs, for the 491 cycles of the CFR engine with an advance ignition of $\beta=28.5$ degrees and for the two values of the excess air coefficient $\lambda=1.1$ and $\lambda=1.276$.

The four graphs also present the external outlines of the curves for the indicated pressure as well as the maximum values related to the upper and lower external outlines, respectively. The graphs in figures $4 \mathrm{a}$ and $4 \mathrm{~b}$ highlight the existence of several maximum values which are slightly higher in the case of the LASER spark plug (22.4-26.9 bar) compared to those of the classical spark plug (22.0-26.3 bar) for a stoichiometric mix $(\lambda=1.0)$. Conversely, figure $4 \mathrm{c}$ and figure $4 \mathrm{~d}$ show slighly lower maximum values for the LASER spark plug (13.4-22.0 bar) compared to those of the classical spark plug (22.3-13.4 bar) for a leaner mix $(\lambda=1.276)$. 

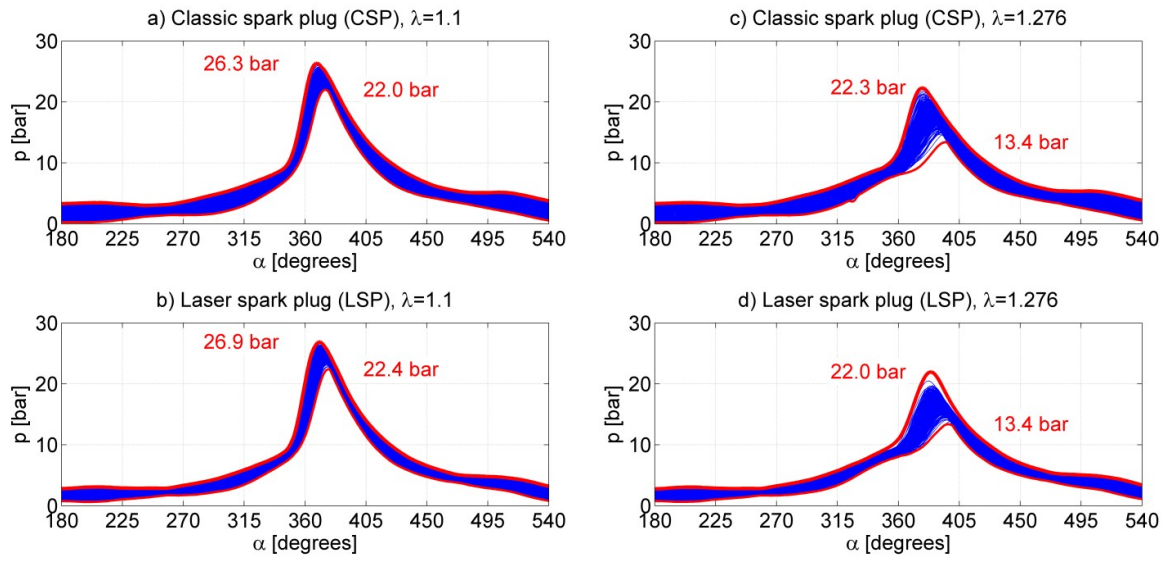

Fig. 4. Pressure curves indicated for the two types of spark plugs

The graphs in figure 4 suggest that in a leaner mix the cyclic dispersion is more intense than in the stoichiometric mix, the curves on the right having a wider spread; moreover, the maximum values variation range of the external outlines of the curves is wider at $\lambda=1.276$ ( 8.9 bar compared to 4.3 bar for the classical spark plug, and 8.6 bar compared to 4.5 bar for the LASER spark plug, respectively).

However, if cyclic dispersion is estimated based on the COV variation coefficient, this particular conclusion is refuted, as seen in figure 5, for four values presented in the graphs. This proves the inconsistency of utilizing the variation coefficient as a criterion for cyclic dispersion because it represents a ratio of two values (standard deviation and average value) and as a result both of them influence the COV value.
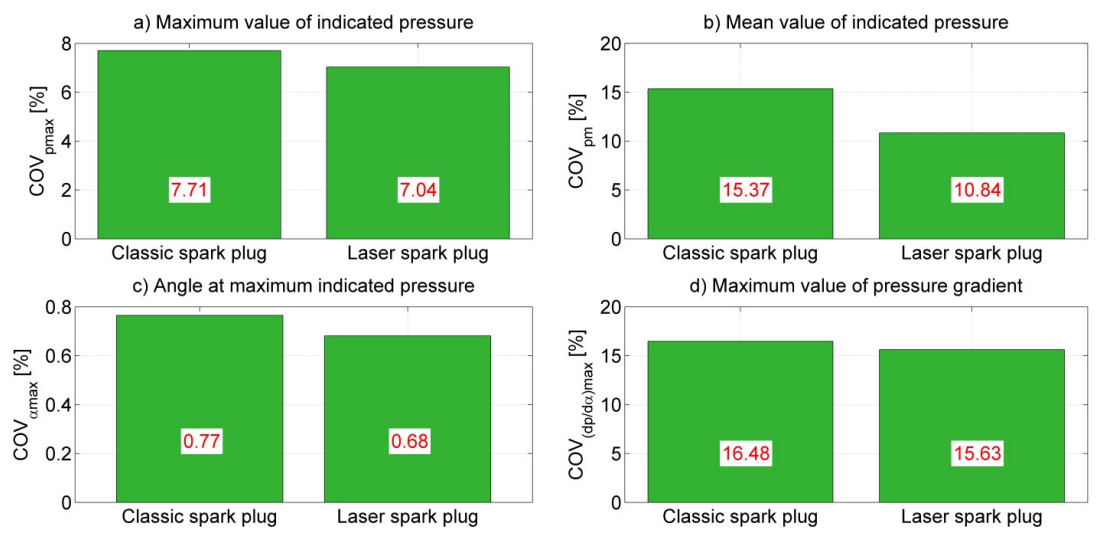

Fig. 5. Estimated cyclic dispersion

Figure 6 presents the diagrams indicated for the two types of spark plugs (classical and LASER) for 50 cycles of the Dacia mono-cylinder engine, a revolution of 2800 RPM and a $90 \%$ charge, for three values of the excess air coefficient: $\lambda=0.9, \lambda=1.0$ și $\lambda=1.1$. 

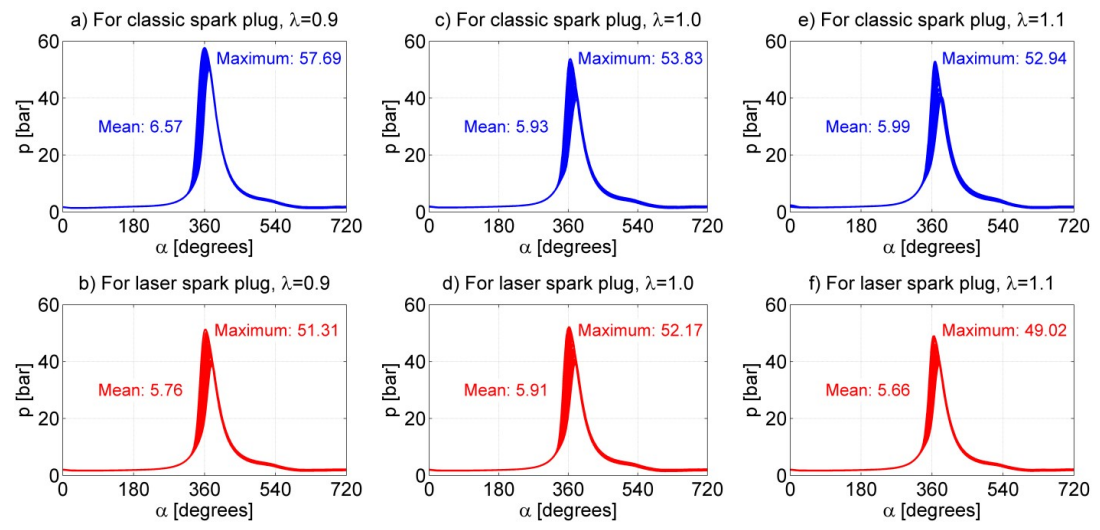

Fig.6 Maximum and average indicated pressure values of 50 functional cycles.

The graphs in figure 6 show the maximum and average indicated pressure values of the 50 functional cycles. As seen, the values are lower for the LASER spark plug compared to those of the classical ignition, for all the three combined values of the air-fuel dosage which suggests lower levels of power performance in the case of the LASER spark plug.

This fact is confirmed in figure 7 , which presents the indicated pressure-volume ( $p$ $V)$ diagram for $\lambda=0.9$, similarly showing the same information for the other two values. Indeed, as shown in the graph, the power of the mono-cylinder engine $P_{e}$, is $7.9 \%$ lower in the case of the LASER spark plug (6.48 HP compared to $7.03 \mathrm{HP}$ ) and becomes obvious at 2800 RPM and a $90 \%$ charge.

The decrease is justified by the smaller area of the indicated diagram $p-V$ (area difference $A_{1}-A_{2}$, detail $A$ ), an area related to mechanical work $277.03 \mathrm{Nm}$ of the classical spark plug and $255.18 \mathrm{Nm}$ of the LASER spark plug. The graph also presents the estimated maximum power values of the poly-cylindrical engine with 4 engines $P_{\max }$, thus at a rotation of 5200 RPM and a 100\% charge: 47.33 HP for the classical spark plug and 43.6 HP for the LASER spark plug. It is well known that the technical specification of the engine indicates a maximum power of $54 \mathrm{HP}$, the difference being caused by the wear and tear of the engine and the estimation error. Figure 7 also shows the values of the actual specific fule consumption $c_{e}$. As indicated in the graph, the specific consumption for the LASER spark plug is $6.9 \%$ lower than that of the classical spark plug.

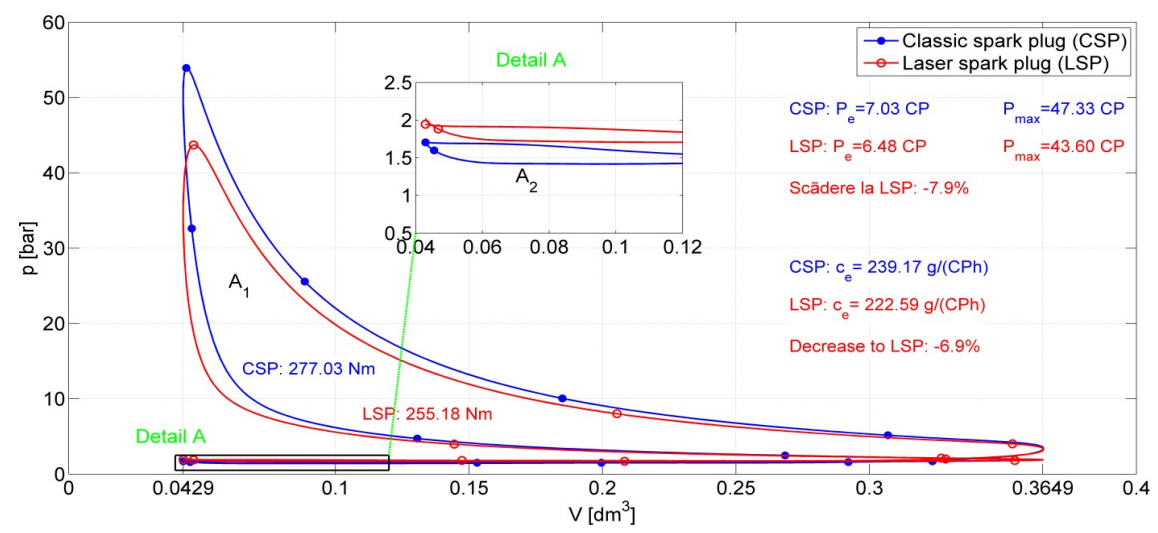

Fig. 7. Indicated pressure-volume $(p-V)$ diagram 
As already stated, the LASER spark plug has been chosen also because it ensures a decrease in exhaust gases, in particular nitrogen oxides. In this sense, figure 8 and figure 9 present exhaust gases values measured on the CFR engine, while figure 10 shows the values of polluting substances mentioned in the graphs in the case of the Dacia monocylinder engine.
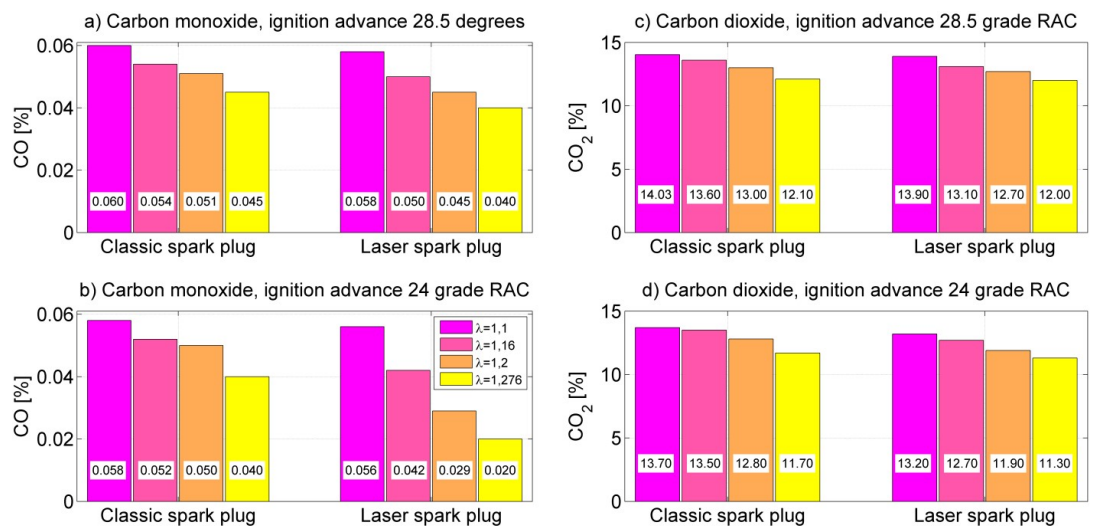

Fig. 8. Pollutant emission monoxide.
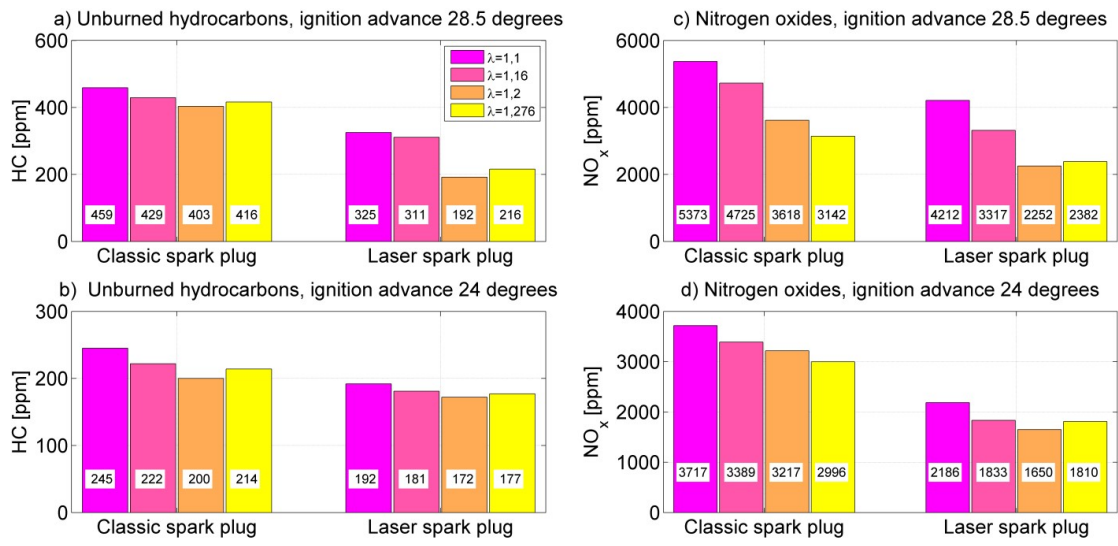

Fig. 9. Pollutant emission hydrocarbons.

The graphs in figure 8, figure 9 and figure 10 highlight the reduction of all exhaust gases for the LASER Spark plug compared to the classical spark plug, with a noticeable decrease of nitrogen oxides.

The graphs in figure 8 , figure 9 and figure 10 also confirm the reduction of all exhaust gases as the air-fuel mix becomes leaner (increasing the $\lambda$ coefficient) up to a value of $\lambda=1.2$, following which exhaust gases will increase (here up to $\lambda=1.276$ ). In addition, the graphs in figure 8 and figure 9 confirm the increase of exhaust gases values as the ignition advance rises, here from $\beta=24$ degrees to $\beta=28.5$ degrees. 

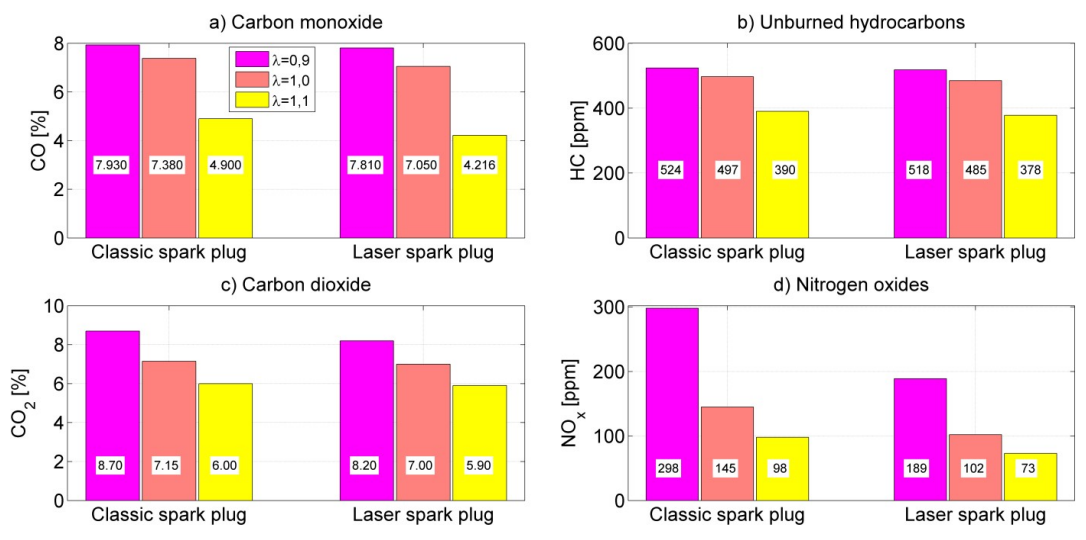

Fig.10. Pollutant emission carbon monoxide

\section{Conclusions}

Several important conclusions have resulted from the aforementioned experiments:

- the use of the LASER spark plug ensures a decrease of the specific fuel consumption for any composition of the air-fuel mix and for any ignition advance value;

- the study based on all the experimental data (the present paper shows only a part of the study) indicates that the use of the LASER spark plug ensures the reduction of exhaust gases down to a leaner air-fuel mix equivalent to an excess air coefficient of $\lambda=1.2$ - the use of the variation coefficient to estimate cyclic dispersion has the disadvantage of being a ratio of two values. Consequently, it cannot lead to valid conclusions;

- the study confirms the well-known fact that cyclic dispersion, performance and exhaust gases are influenced by the ignition advance and the quality of the air-fuel mix (by means of the excess air coefficient);

- the use of the LASER spark plug leads to an engine power reduction the values depend on the quality of the air-fuel mix and the ignition advance.

\section{Acknowledgments}

In the course of my extended research and comprehensive testing I was kindly provided with guidance and assistance by several highly-reputed scientists who deserve my deepest gratitude: Prof. Constantin Pana, Prof. Niculae Negurescu, Lecturer Alexandru Cernat, Lecturer Dinu Fuiorescu, Lecturer Cristian Nutu, Faculty of Mechanical Engineering and Mechatronics, Department of Thermotechnics, Engines, Thermal Equipments and Refrigeration Installations, University POLITEHNICA of Bucharest.

The experiments were developed with a LASER spark device designed at National Institute for LASER, Plasma and Radiation Physics, Laboratory of Solid-State Quantum Electronics, Magurele, Ilfov, 077125, Romania. The authors are deeply indebted Mr. Pavel Nicolaie, Mr. Dinca Mihai and Mrs. Croitoru Gabriela for their advice and assistance during the experiments.

Also, the authors wish to thank AVL GmbH for providing the necessary equipment. 


\section{References}

1. M. Lackner, Winter, F., What is ignition? Combustion File 256, IFRF Online CombustionHandbook, ISSN 1607-9116, International Flame Research Foundation, Ijmuiden, The Netherlands, (2004).

2. H. Kopecek, M. Lackner, F. Winter, E. Wintner, Laser ignition of methane air mixtures at pressures up to $4 \mathrm{MPa}$, Journal of Laser Physics 13 (11), 1365 (2003).

3. H. Kopecek, Lackner, M., Wintner, E., Winter, F., Laser-Stimulated Ignition in a Homogeneous Charge Compression Ignition Engine, SAE 2004 World Congress, paper No 2004-01-0937, Detroit, MI, USA (2004).

4. J. D. Dale, M. D. Checkel, P. R. Smy, Application of High Energy Ignition Systems To Engines, Prog. Energy Combust. Sci. 23, 379-398 (1997).

5. P.D. Ronney, Laser versus conventional ignition of flames, Optical Engineering 33 (2), 510 (1994).

6. H. Kopecek , Charareh S., Lackner M., Forsich C., Winter F., Klausner J., Herdin G., Wintner E., Laser Ignition of Methane-Air Mixtures at High Pressures and Diagnostics, Salzburg, Austria: Proceedings of ICES03, Spring Technical Conference of ASME Internal Combustion Engine Division (2003).

7. J.B. Heywood, Internal combustion engine fundamentals, McGraw-Hill international editions (1988).

8. T.X. Phuoc, Single-point versus multi-point laser ignition: Experimental measurements of combustion times and pressures, Combustion and Flame 122, 508-510 (2000).

9. M.H. Morsy, Chung S.H., Laser induced multi-point ignition with a single-shot laser using two conical cavities for hydrogen/air mixtures, Experimental Thermal and Fluid Science 27, 491-497 (2003).

10. M. Weinrotter, Kopecek H., Wintner E., Lackner M., Winter F., Laser ignition of hydrogen-air mixtures at high pressures, Orleans, France: Proceedings of the European Combustion Meeting, European Combustion Institute (2003).

11. B. Done, Alexandru Cernat, Fuiorescu Dinu, Cristian Nutu "Aspects of the cycle variability study of a si engine with LASER plug Ignition system.” U.P.B Sci. Bull. Series D, Vol. 79, Iss. 2, 2017. ISSN 1454-2358.

12. B. Done "Experimental Investigations of LASER Ignition Use at Spark Ignition Engine" 11th International Conference Interdisciplinarity in Engineering, INTER-ENG 2017, Procedia Manufacturing 22 (2018) 659-666. 6

13. N. Pavel, T. Dascalu, G. Salamu, M. Dinca, N. Boicea, and A. Birtas, "Ignition of an automobile engine by high-peak power Nd:YAG/Cr4+:YAG laser-spark devices," Opt. Express 23(26), 33028-33037 (2015). 